\title{
Rare case of broad ligament pregnancy
}

\section{Pragya Ojha*, Kalika Vaish}

Department of Obstetrics and Gynaecology, Sardar Patel Medical College, Bikaner Rajasthan, India

Received: 24 April 2021

Accepted: 28 May 2021

\author{
*Correspondence: \\ Dr. Pragya Ojha, \\ E-mail: pragyash125@gmail.com
}

Copyright: () the author(s), publisher and licensee Medip Academy. This is an open-access article distributed under the terms of the Creative Commons Attribution Non-Commercial License, which permits unrestricted non-commercial use, distribution, and reproduction in any medium, provided the original work is properly cited.

\begin{abstract}
Broad ligament pregnancy is rare form of abdominal pregnancy. There is high risk of maternal morbidity and mortality. Due to its rarity, usually, diagnosis cannot be established before surgery. We reported a 27 year old, G3P2L2 who presented with 4 month amenorrhea with pain in lower abdomen. Ultrasonography revealed a single live extra-uterine pregnancy of 17 weeks in right adnexa. A right sided Broad ligament pregnancy was found on exploratory laparotomy. Excision of mass with right sided salpingo-oophrectomy was performed. Post operative course was uneventful. Early diagnosis with high risk of suspicion and early intervention is needed to overcome it's related complications.
\end{abstract}

Keywords: Pregnancy, Broad ligament, Ectopic, Laparotomy

\section{INTRODUCTION}

Abdominal pregnancy is rare $(1 \%)$ form of pregnancy. ${ }^{1}$ Broad ligament pregnancy is a subtype of abdominal pregnancy where implantation occurs between the two leaves of broad ligament. ${ }^{2,3}$ Clinical spectrum varies from asymptomatic to a full term pregnancy with delivery of a viable foetus. Broad ligament pregnancy can present with triad of ectopic pregnancy, i.e. amenorrhea, pain abdomen and bleeding per vaginum, sometimes it can present with acute abdomen due to life threatening intraperitoneal haemorrhage due to rupture of the gestational sac. USG abdomen showing empty uterus with heterogenous adnexal mass helps in the probable diagnosis. Surgery is the definitive treatment, by which the diagnosis is also confirmed.

\section{CASE REPORT}

A 27 year old, G3P2L2 with history of previous Caesarean delivery followed by two full term normal vaginal deliveries presented with 4 months amenorrhea with pain in lower abdomen for 2-3 days. On admission, patient's general condition was fair, with stable vitals. On per abdominal examination, a 16-18weeks soft cystic and mobile mass was felt. On per vaginal examination, right sided soft cystic adnexal mass was felt, uterus could not be made out separately, os was closed and there was no bleeding per vaginum. Ultrasonography was done which showed no evidence of G-sac in endometrial cavity with single live extrauterine pregnancy of 17 weeks in right adnexa with cardiac pulsation. This picture suggested extrauterine pregnancy. After all basic investigations, patient was taken for elective exploratory laparotomy.

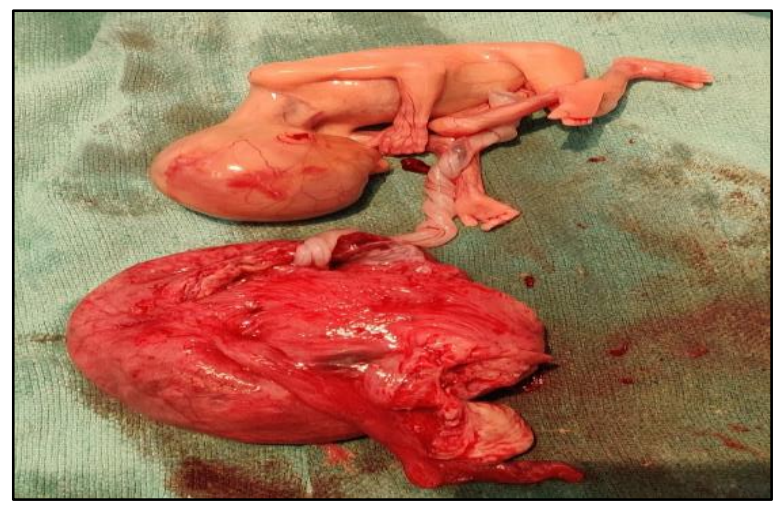

Figure 1: Operative picture of broad ligament pregnancy. 


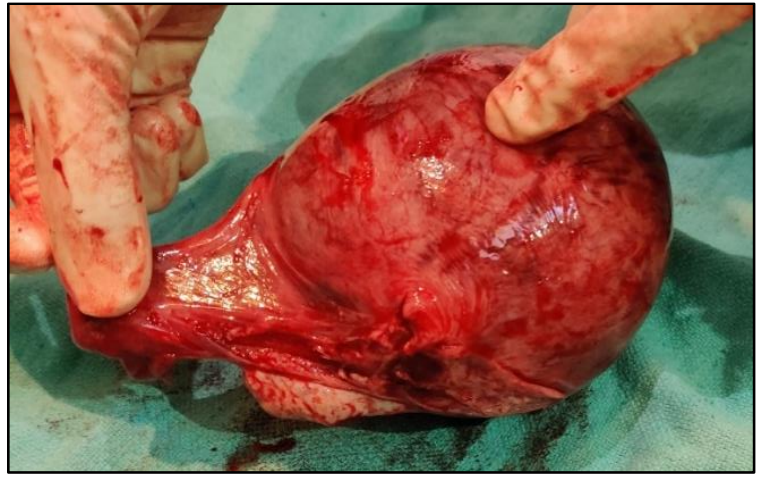

Figure 2: Excised broad ligament gestational sac.

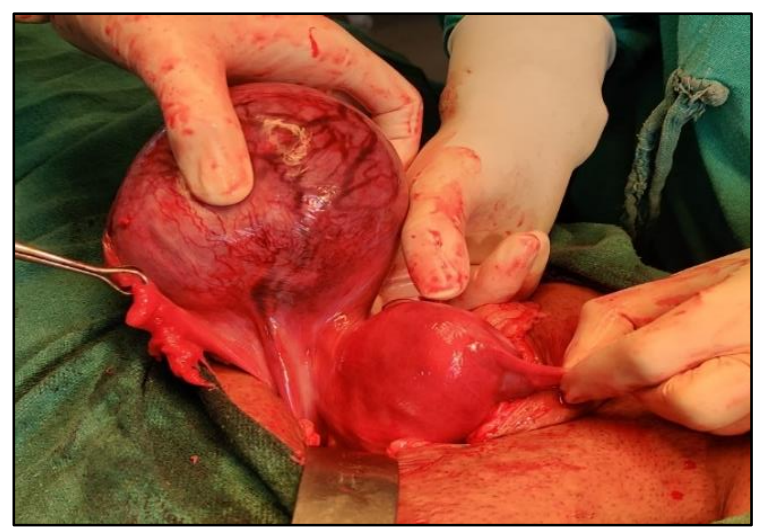

Figure 3: broad ligament sac showing foetus.

On laparotomy, a tense cystic mass of $8 \times 7 \mathrm{~cm}$, with increased vascularity was present between fallopian tube anteriorly and ovarian ligament posteriorly, i.e. in broad ligament. Mass was removed along with right sided salpingo-oophrectomy. Left sided adnexa was healthy and left sided tubectomy done. Mass was dissected, foetus along with placenta and amniotic fluid extracted. Patient had uneventful post-operative period and discharged successfully.

\section{DISCUSSION}

Broad ligament pregnancy is rare form of abdominal pregnancy accounting for 1 in 300 ectopic pregnancy. ${ }^{4}$ Maternal mortality is as high as $20 \% .^{5}$ It results either from primary implantation or secondary implantation with initial implantation may be in fallopian tube, ovary or peritoneal surface. Risk factors for ectopic pregnancy include history of secondary infertility, PID, endometriosis, previous history of ectopic pregnancy, progesterone only Pill or IUCDs. There was no apparent risk factors in this case. There are no reliable Clinical, Sonographic or biological markers that can predict broad ligament pregnancy. ${ }^{6,7}$ Ultrasonography, MRI, beta-HCG aid in diagnosis. The management is exploratory laparotomy. However, if the patient is stable, and presented in early gestation, laparoscopic removal can be done. Early diagnosis and prompt surgical intervention can prevent fatal complications. Similar second trimester Broad ligament pregnancy was also reported by Sagili and Rani with 20 weeks, Sharma et al with 18 weeks, Cordero et al with 18 weeks, Salomon et al with 15 weeks, and Naeiji et al with 14 weeks pregnancy with pain abdomen and no identifiable risk factor. ${ }^{2,8-10}$

\section{CONCLUSION}

Broad ligament pregnancy is rare type of ectopic pregnancy but a life threatening condition. Early diagnosis and prompt surgical intervention definitely improves the morbidity and mortality.

Funding: No funding sources Conflict of interest: None declared Ethical approval: Not required

\section{REFERENCES}

1. Ludwig M, Kaisi M, Bauer O, Diedrich K. The forgotten child- A case of heterotropic, intraabdominal and intrauterine pregnancy carried to term. Hum Reprod. 1999;14:1372-4.

2. Cordero DR, Adra A, Yasin S, O'Sullivan MJ. Intraligamentary pregnancy. Obstet Gynecol Surv. 1994;49(3):206-9.

3. Chia KV, Fayle RJS, Ferriman E. Intraligamentary pregnancy. J Obstet Gynaecol. 1993;13(4):254.

4. Alto WA. Abdominal Pregnancy. Am Fam Physician. 1990;4:209-14.

5. Latchaw G, Takacs P, Gaitan L, Geren S, Burzawa J. Risk factors associated with the rupture of tubal ectopic pregnancy. Gynecol Obstet Invest. 2005;60:177-80.

6. Job -Spira N, Fernandez H, Bouyer J. Ruptured tubal ectopic pregnancy;risk factors and reproductive outcome results a population based study in france. Am J Obstet Gynecol. 1999;180:938-44

7. Sagili H, Rani R. Preoperative Methotrexate in BroadLigament Pregnancy: Is There a Role? J Gynecol Surg. 2013;29(2):102-4.

8. Sharma S, Pathak N, Goraya SPS, Mohan P. Broad ligament ectopic pregnancy. Sri Lanka Journal of Obstet Gynaecol. 2011;33(2):60-2.

9. Salomón AJR, Ortiz HA, Medrano MG, Rivera ESF. [Ectopic intraligamentary pregnancy]. Ginecol Obstet Mex. 2013;81(4):211-4.

10. Naeiji Z, Saleh M, Keshavarz E. Broad ligament pregnancy: a case report. Res J Med Sci. 2015;9(3):118-22.

Cite this article as: Ojha $\mathrm{P}$, Vaish $\mathrm{K}$. Rare case of broad ligament pregnancy. Int J Reprod Contracept Obstet Gynecol 2021;10:2893-4. 